\title{
The epipharynx-kidney axis triggers glomerular vasculitis in immunoglobulin A nephropathy
}

\author{
Osamu Hotta ${ }^{1,2} \cdot$ Takashi Oda $^{3}$ (D)
}

Published online: 19 November 2019

(C) The Author(s) 2019

\begin{abstract}
Macroscopic hematuria concomitant with acute pharyngitis is a characteristic feature of immunoglobulin A nephropathy (IgAN). Although the underlying mechanism of worsening hematuria has not been fully elucidated, activation of the innate immune system of nasopharynx-associated lymphoid tissue is thought to play an important role. The epipharynx is an immunologically activated site even under normal conditions, and enhanced activation of innate immunity is likely to occur in response to airborne infection. As latent but significant epipharyngitis presents in most IgAN patients, it is plausible that acute pharyngitis due to airway infection may contribute as a trigger of the epipharyngeal innate immune system, which is already upregulated in the chronically inflamed environment. The aim of this review was to discuss the mechanism of epipharynx-kidney axis involvement in glomerular vasculitis responsible for the worsening of hematuria in IgAN.
\end{abstract}

Keywords IgA nephropathy $\cdot$ Hematuria $\cdot$ Glomerular vasculitis $\cdot$ Epipharyngitis $\cdot$ Epipharynx-kidney axis $\cdot$ Innate immunity

\section{Introduction}

Immunoglobulin A ( $\operatorname{Ig} \mathrm{A})$ deposition in the glomerular mesangium is the histological hallmark of IgA nephropathy (IgAN) and has led to extensive research on mucosaassociated lymphoid tissue (MALT) since the initial recognition of this disease approximately 50 years ago. MALT governs mucosal immunity and, in particular, the palatine tonsils (organized MALT) [1-10] and the gut-associated lymphatic tissue [11-19] have drawn significant interest.

Hematuria is a clinical hallmark of IgAN. Although the clinical significance of hematuria in IgAN has not been considered as convincing as that of proteinuria, recent research has demonstrated that remission of hematuria, either spontaneously or after receiving immunosuppressive treatments, improves long-term renal survival in IgAN [20].

Takashi Oda

takashio@ tokyo-med.ac.jp

1 Division of Internal Medicine, Hotta Osamu Clinic, Sendai, Japan

2 Division of Nephrology and Endocrinology, Tohoku Medical and Pharmaceutical University, Sendai, Japan

3 Department of Nephrology and Blood Purification, Tokyo Medical University Hachioji Medical Center, Tokyo, Japan
Although the etiology of hematuria in IgAN has not been fully elucidated, it is thought that the rupture of glomerular basement membranes caused by intra-capillary leukocyte influx, so-called glomerular vasculitis, is the pathological event responsible for gross hematuria [21, 22]. Therefore, the existence of a close relationship between the remission of hematuria and long-term renal prognosis [20] seems reasonable if the former represents the termination of glomerular vasculitis. Moreover, it has been shown that the severity of hematuria tends to improve in response to immunosuppressive therapy [23], especially steroid pulse therapy [24], whereas it does not significantly improve with renin-angiotensin system inhibitors, which are often effective in reducing proteinuria [23].

The triggering factor of gross hematuria in IgAN, presumably related to aggravating of glomerular vasculitis, has not been fully understood. Macroscopic bouts, typically associated with pharyngeal infection, namely "synpharyngitic gross hematuria," are a frequent presentation in patients with IgAN. Therefore, it is important to determine the factors that might promote macroscopic hematuria concurrent with pharyngitis. Some patients exhibit synpharyngitic gross hematuria even in the post-tonsillectomy state, without any gastrointestinal symptoms. Moreover, residual hyperactivation of innate immunity even in patients who have undergone tonsillectomy has been demonstrated [25]. Thus, it is conceivable that an 
area other than the palatine tonsil or gut may be involved as a trigger of gross hematuria, i.e., glomerular vasculitis.

Located at the back of the nasal cavities, the epipharynx is a unique tissue that is vulnerable to the effects of airborne infections and air pollution. In addition, as a component of the nasopharynx-associated lymphoid tissue (NALT), the epipharynx plays a role in the production of memory/effector $\mathrm{T}$ lymphocytes in response to exogenous antigens in inspired air, which contributes to host defense mucosal immunity as a source of antigen-specific IgA-producing B cells [26].

In this review, we discuss the possible role of epipharyngitis in the development of gross hematuria associated with glomerular vasculitis in IgAN.

\section{Characteristics of the epipharynx}

As the epipharynx is the primary site of airway infections, it has a highly developed immunocompetent function against inhaled foreign proteins such as those from bacteria and viruses. Indeed, the epipharynx is a physiological inflammatory site, and about two-thirds of healthy people have mild chronic epipharyngitis without any symptoms [27, 28].

Unlike the middle and lower pharynx, which are covered by stratified squamous epithelium, the surface of the epipharynx is lined with ciliated columnar epithelial cells, and secreted IgA covers the surface of the epipharyngeal epithelium. Concurrently, as a component of the NALT, the epipharynx plays a role in both innate and acquired immunity.

During childhood, the pharyngeal tonsil (adenoid), which is part of Waldeyer's tonsillar ring, is situated in the roof of the epipharynx posterior to the nasal cavity. The adenoids start to shrink before adolescence and usually disappear by adulthood.

Abundant lymphocytes exist mainly in the submucosal area, and it should be emphasized that many lymphocytes colocate with epipharyngeal epithelial cells [29]. Moreover, the epipharynx is rich in dendritic cells, and some of them penetrate epithelial tight junctions, which facilitate access to the antigen [30]. Additionally, membranous cells are present in the epipharyngeal epithelium, which play a role as portals of entry for antigens in the NALT [31], similar to those in palatine tonsils and Peyer's patches.

Epipharyngeal mononuclear cells contain predominantly B cells (about 65\%), approximately 5\% macrophages, and 30\% $\mathrm{CD} 3+\mathrm{T}$ cells. $\mathrm{T}$ cells are primarily of the CD4+ subset (about $80 \%$ ) [32]. Importantly, both T and B lymphocytes are highly activated, even in normal individuals [29]. Of note, these characteristics of epipharyngeal lymphocytes are similar to those of palatine tonsillar lymphocytes [29, 32]. In contrast, welldeveloped lymphoid follicles, similar to those in the palatine tonsil, are restricted to the adenoid tissue, in addition to which the lymphoid organ of the epipharynx is mainly composed of elements similar to those in the interfollicular region of the palatine tonsil.

\section{Epipharyngeal response in airborne infection}

Upper respiratory tract infection is the most frequent infection that people experience in their lifetime. The epipharyngeal tissue fights against the inhaled pathogen via multiple mechanisms: (1) removal of large particles and microorganisms via mucociliary clearance; (2) recognition of pathogens through pattern recognition receptors, mainly signaling Toll-like receptors (TLRs); (3) secretion of pro-inflammatory cytokines and antimicrobial peptides; and (4) activation of adaptive immunity, including proliferation and differentiation of specific clones in the epipharyngeal lympho-epithelial tissue.

In response to the invasion of pathogens into the epipharynx, neutrophils and macrophages emerge at inflammatory sites as the first line of immunocompetence via CXC chemokines and pro-inflammatory cytokines. Concurrently, activation of helper $\mathrm{T}$ lymphocytes is induced, whereas activation of $\mathrm{B}$ lymphocytes occurs during the recovery phase.

\section{Epipharyngeal innate immunity in IgAN}

We have recently reported the extremely high incidence of latent but significant epipharyngitis in patients with IgAN with microscopic hematuria suggesting that chronic inflammation of the epipharynx may be an extremely common background condition of IgAN [28].

In the secondary lymphoid organs, such as the tonsils and Peyer's patches, B cells in the lymphoid follicles play an important role in acquired immunity, whereas dendritic cells, macrophages, and $\mathrm{T}$ cells located in the interfollicular area have a crucial function in innate immunity. It is believed that the epipharyngeal adapted immunity induced by follicular lymphocytes is reduced after the regeneration of adenoids. On the contrary, high innate immunity function at the epipharynx continues throughout the lifetime.

Takechi et al. [7] demonstrated that the number of monocyte-derived dendritic cells (CD208+ cell) in the interfollicular area of the palatine tonsils was related to crescent formation in IgAN, suggesting the involvement of interfollicular dendritic cells in the development of glomerular vasculitis. We speculate that immune cells in the interfollicular area of the epipharynx, as a component of NALT, may participate in glomerular vasculitis in IgAN, similar to palatine tonsils.

The epipharyngeal innate immune system plays a key role in protecting the mucous membranes against various pathogens through pattern recognition receptors, including TLRs, 
which detect pathogens and function as signaling molecules [33]. Recognition of pathogens and endogenous TLR ligands promotes the activation of genes that encode proinflammatory cytokines, antimicrobial peptides, and other defense molecules [34].

Upregulation of TLRs has been observed in upper respiratory tract infections [35]. Additionally, abnormal expression levels of TLRs were demonstrated in an animal model of IgAN and in patients with IgAN and IgA vasculitis [36-41]. It is conceivable that chronic inflammation of the epipharynx, which is extremely common in patients with $\operatorname{IgAN}$, is the underlying condition responsible for the upregulation of TLRs in a considerable percentage of patients with IgAN.

\section{Role of fractalkine/CX3CR1 interaction in $\lg \mathrm{AN}$}

The mechanism by which hyperactivation of innate immunity causes glomerular vasculitis is an important area of research. CX3C chemokine receptor 1 (CX3CR1), the only CX3 chemokine ligand 1 (fractalkine) receptor, is expressed in human NK cells, NKT cells, monocytes, CD + + T cells, and $\gamma \delta$ T cells [42]. Fractalkine, which is the single ligand of CX3CR1, is a unique molecule that acts as both an adhesion molecule and chemokine [43]. Fractalkine is localized on the vascular endothelial surface and strongly attracts CX3CR $1+$ cells without the help of other adhesion molecules, while the soluble form acts as a chemokine, inducing the migration of CX3CR1+ cells. Thus, both the membrane-bound and soluble forms of fractalkine act as a strong chemoattractant of CX3CR1+ cells.

As the epipharyngeal epithelium is the primary site of airway infection in humans, understanding the role of the fractalkine/CX3CR1 interaction during epipharyngitis may provide important clues to the mechanism of synpharyngitic gross hematuria.

Membrane-bound fractalkine can be induced on vascular endothelial cells by inflammatory cytokines such as tumor necrosis factor alpha (TNF- $\alpha)$, interferon- $\gamma$ (IFN $\gamma)$, and interleukin-1 (IL-1) [44]. Moreover, the serum level of soluble fractalkine increases in patients with vasculitis, especially in its active stage [45].

The activated lymphoid tissue of the epipharynx, in response to foreign invaders, produces various inflammatory cytokines for the clearance of pathogens and resolution of pathogen-induced cell damage. Further, pro-inflammatory cytokines including TNF- $\alpha$, IFN $\gamma$, and IL-1 flow into the circulation from the epipharynx and enhance the expression of membrane-bound fractalkine on distant glomerular endothelial cells, together with other adhesion molecules such as E- and P-selectins, resulting in recruitment of CX3CR1+ leukocytes and neutrophils in the glomeruli.
Cox et al. studied patients with IgAN during episodes of macroscopic hematuria and identified an upregulated expression of the chemokine receptor CX3CR1 in their circulating leukocytes [46]. Moreover, Iwatani et al. reported that adoptive transfer of either cells of a NK cell line or CD16(+ )CD56(+) cells derived from patients with IgAN into nude rats induced hematuria in the recipients; additionally, they demonstrated that NK cells exert cytotoxic activity toward human glomerular endothelial cells in a dose-dependent manner [47]. In addition, our preliminary study demonstrated a significant increase in the proportion of macrophages (monocytes), NK cells, CD8+ T cells, and $\gamma \delta$ T cells, i.e., CX3CR1+ leukocytes, in the urine of patients with IgAN [48], indicating an enhanced fractalkine/CX3CR1 interaction in IgAN.

Notably, Otaka et al. demonstrated the upregulation of CX3CR1 on tonsillar CD8+ T cells in patients with IgAN and postulated that a hyper-immune response to microbial DNA enhanced the expression of CX3CR1 on CD8+ T cells in the interfollicular area of palatine tonsils, followed by migration of the cells to renal lesions via the blood circulation, eventually resulting in the development of hematuria [8]. Given that epipharyngeal CD8+ T cells, as a part of NALT, behave in similar fashion to tonsillar interfollicular CD8+ T cells, we postulate that the upregulation of fractalkine/ CX3CR1 interactions related to epipharyngitis may play a crucial role in glomerular vasculitis, resulting in worsening hematuria.

As the accumulation of neutrophils in active lesions of the glomeruli is one of the histological hallmarks of IgAN in gross hematuria (glomerular vasculitis) [22], the mechanism of glomerular neutrophil accumulation is another matter of concern. Although the precise mechanism is still unknown, we suspect that neutrophil accumulation mainly occurs locally and secondary to local inflammation induced by infiltrated glomerular CX3CR1+ cells.

Interleukin-17A (IL-17A), also commonly called IL-17, is produced by the $\mathrm{T}$ helper 17 (Th17) subset of CD4+ T cells [49]. IL-17A has an important role as a pro-inflammatory cytokine uniquely positioned at the interface of innate and adaptive immunity. IL-17A induces the release of secondary pro-inflammatory cytokines in most epithelial, endothelial, and mesenchymal cells leading, in turn, to the recruitment and accumulation of neutrophils [50]. Importantly, in addition to Th17 T cells, CD8+ T cells, $\gamma \delta$ T cells, and NKT cells, i.e., CX3CR1+ leukocytes, also produce IL-17A [51, 52]. Of note, IL-17A can induce the production of pro-inflammatory cytokines such as TNF and IL-1 from endothelial cells and infiltrating macrophages [53]. The important role of IL-17 and Th17 cell in renal inflammation is suggested in glomerular vasculitis including lupus nephritis, ANCA-associated vasculitis, and $\operatorname{IgAN}[54,55]$.

The increased concentration of local inflammatory cytokines such as IL- 1 and TNF- $\alpha$, which are produced as a 


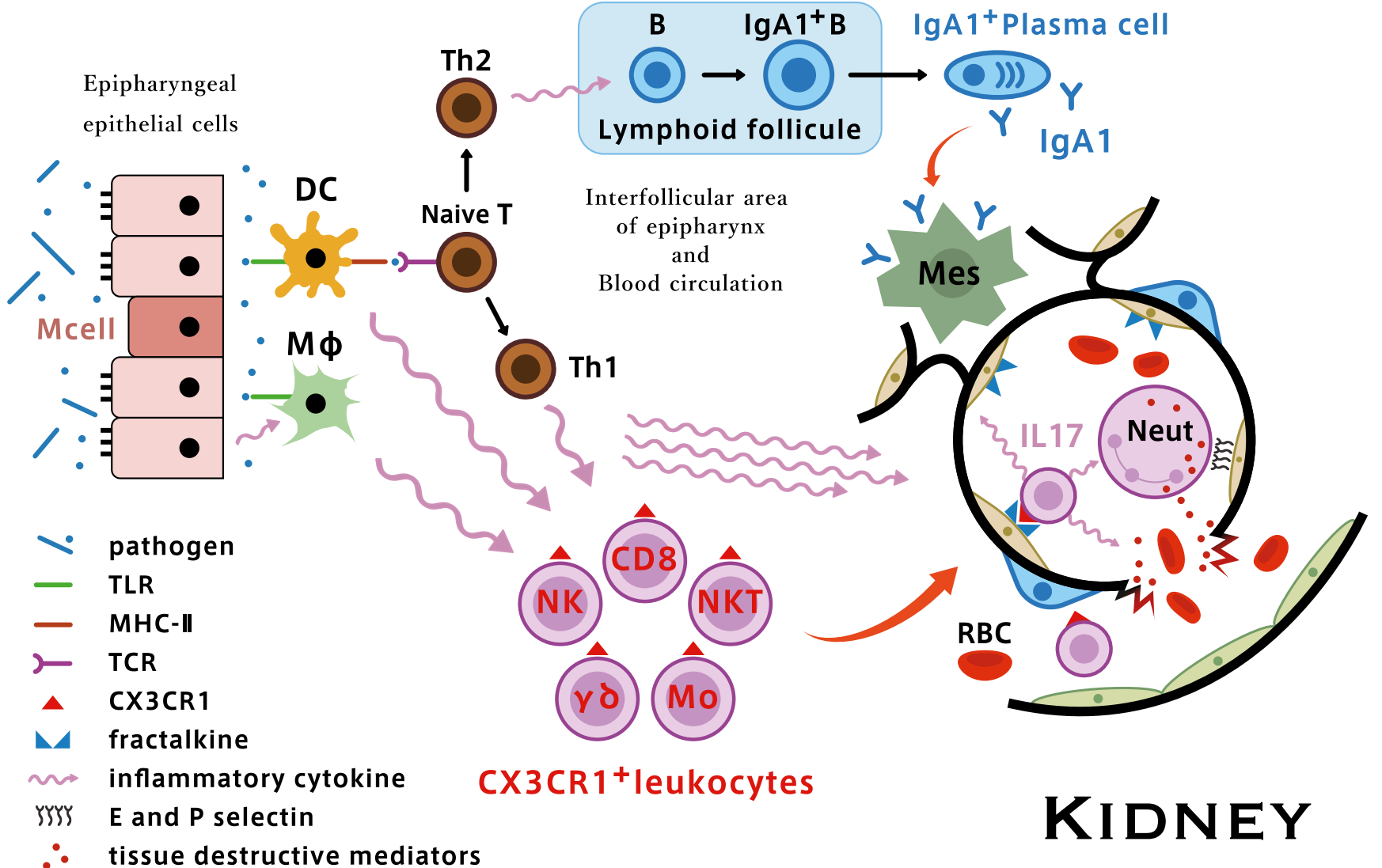

Fig. 1 Schematic illustration of the putative mechanisms of epipharyngitis triggering gross hematuria. In acute epipharyngitis, following pathogen recognition through TLRs, dendritic cells in the mucosa immediately produce pro-inflammatory cytokines. Simultaneously, infected epithelial cells and activated macrophages produce chemokines that upregulate the expression of CX3CR1 on monocytes, NK cells, CD8+ T cells, and $\gamma \delta \mathrm{T}$ cells. Circulating pro-

consequence of the fractalkine/CX3CR1 interaction, would induce glomerular endothelial expression of Eand P-selectins. Neutrophils are the major cells in the blood and naturally express selectin ligands (P-selectin glycoprotein ligand-1, E-selectin ligand-1, CD44, and Sialyl Lewis X) on their cell surface $[56,57]$. Therefore, the interaction of selectins on endothelial cells with selectin ligands on neutrophils occurs naturally and leads to local accumulation of neutrophils in the glomeruli.

Furthermore, neutrophils may change their phenotype (i.e., by increased expression and altered distribution of selectin ligands) in the inflammatory environment (high cytokine/chemokine) [58] of renal tissue and thereby easily adhere to activated endothelial cells in the glomeruli. Then, neutrophils accumulate in the glomeruli and are activated by interaction with activated endothelial cells and by the pro-inflammatory cytokine environment, resulting in the production and release of reactive oxygen species with proteolytic enzymes, leading to

inflammatory cytokines also enhance the expression of fractalkine and other adhesion molecules such as E- and P-selectins on glomerular endothelial cells. Upregulation of the fractalkine/CX3CR1 interaction and IL17 secreted by infiltrated glomerular CX3CR1+ leukocytes, which promotes influx of neutrophils, leads to the development of glomerular vasculitis and subsequent rupture of the glomerular capillary wall, which is clinically associated with gross hematuria

local generation of necrotizing lesions, followed by rupture of the glomerular capillary wall (Fig. 1).

\section{Conclusion}

Although macroscopic hematuria is a distinctive clinical symptom accompanying pharyngitis in IgAN, the effect of epipharyngitis, inevitable inflammation during acute pharyngitis, on hematuria or glomerular vasculitis has not been fully elucidated. As epipharyngitis is present in most patients with IgAN, chronic inflammation of the epipharynx may be an extremely common background condition of IgAN. Thus, acute pharyngitis due to airway infection may contribute as a trigger of the epipharyngeal immune system, which is already upregulated in the chronically inflamed environment, resulting in a hyperactivated innate immune system and upregulation of the fractalkine/CX3CR1 interaction. 
Localized glomerular CX3CR1+ leukocyte inflammation with an increased concentration of inflammatory cytokines induced by fractalkine/CX3CR1 interactions leads to local accumulation and activation of neutrophils that produce and release tissue-destructive mediators. As a result, glomerular vasculitis, the lesion responsible for gross hematuria, may develop.

Given that epipharyngitis and its effects on IgAN are not fully understood, we propose that the so-called epipharynxkidney axis may be an important focus of future research.

\section{Compliance with ethical standards}

Conflict of interest The authors declare that they have no conflict of interest.

Open Access This article is distributed under the terms of the Creative Commons Attribution 4.0 International License (http:// creativecommons.org/licenses/by/4.0/), which permits unrestricted use, distribution, and reproduction in any medium, provided you give appropriate credit to the original author(s) and the source, provide a link to the Creative Commons license, and indicate if changes were made.

\section{References}

1. Béné MC, Faure G, Hurault de Ligny B, Kessler M, Duheille J. Immunoglobulin A nephropathy. Quantitative immunohistomorphometry of the tonsillar plasma cells evidences an inversion of the immunoglobulin A versus immunoglobulin G secreting cell balance. J Clin Invest. 1983;71:1342-7.

2. Harper SJ, Allen AC, Béné MC, Pringle JH, Faure G, Lauder I, et al. Increased dimeric IgA-producing B cells in tonsils in IgA nephropathy determined by in situ hybridization for $\mathrm{J}$ chain mRNA. Clin Exp Immunol. 1995;101:442-8.

3. Sato Y, Hotta O, Taguma Y, Takasaka T, Nose M. IgA nephropathy with poorly developed lymphoepithelial symbiosis of the palatine tonsils. Nephron. 1996;74:301-8.

4. Horie A, Hiki Y, Odani H, Yasuda Y, Takahashi M, Kato M, et al. IgA1 molecules produced by tonsillar lymphocytes are under-Oglycosylated in IgA nephropathy. Am J Kidney Dis. 2003;42: 486-96.

5. Goto T, Bandoh N, Yoshizaki T, Nozawa H, Takahara M, Ueda S, et al. Increase in B-cell-activation factor (BAFF) and IFN-gamma productions by tonsillar mononuclear cells stimulated with deoxycytidyl-deoxyguanosine oligodeoxynucleotides (CpGODN) in patients with IgA nephropathy. Clin Immunol. 2008;126:260-9.

6. Nozawa H, Takahara M, Yoshizaki T, Goto T, Bandoh N, Harabuchi Y. Selective expansion of T cell receptor (TCR) V beta 6 in tonsillar and peripheral blood T cells and its induction by in vitro stimulation with Haemophilus parainfluenzae in patients with IgA nephropathy. Clin Exp Immunol. 2008;151:25-33.

7. Takechi H, Oda T, Hotta O, Yamamoto K, Oshima N, Matsunobu T, et al. Clinical and immunological implications of increase in CD208+ dendritic cells in tonsils of patients with immunoglobulin A nephropathy. Nephrol Dial Transplant. 2013;28:3004-13.

8. Otaka R, Takahara M, Ueda S, Nagato T, Kishibe K, Nomura K, et al. Up-regulation of CX3CR1 on tonsillar CD8-positive cells in patients with IgA nephropathy. Hum Immunol. 2017;78:375-83.
9. Muto M, Manfroi B, Suzuki H, Joh K, Nagai M, Wakai S, et al. Toll-Like receptor 9 stimulation induces aberrant expression of a proliferation-inducing ligand by tonsillar germinal center B cells in IgA nephropathy. J Am Soc Nephrol. 2017;28:1227-38.

10. Watanabe H, Goto S, Mori H, Higashi K, Hosomichi K, Aizawa N, et al. Comprehensive microbiome analysis of tonsillar crypts in IgA nephropathy. Nephrol Dial Transplant. 2017;32:2072-9.

11. Emancipator SN, Gallo GR, Lamm ME. Experimental IgA nephropathy induced by oral immunization. J Exp Med. 1983;157: 572-82.

12. Coppo R, Mazzucco G, Martina G. Gluten-induced experimental IgA glomerulopathy. Lab Investig. 1989;60:499-506.

13. Coppo R, Roccatello D, Amore A, Quattrocchio G, Molino A, Gianoglio B, et al. Effects of a gluten-free diet in primary IgA nephropathy. Clin Nephrol. 1990;33:72-86.

14. Collin P, Syrjänen J, Partanen J, Pasternack A, Kaukinen K, Mustonen J. Celiac disease and HLA DQ in patients with IgA nephropathy. Am J Gastroenterol. 2002;97:2572-6.

15. Smerud HK, Fellström B, Hällgren R, Osagie S, Venge P, Kristjánsson G. Gluten sensitivity in patients with IgA nephropathy. Nephrol Dial Transplant. 2009;24:2476-81.

16. Welander A, Sundelin B, Fored M, Ludvigsson JF. Increased risk of IgA nephropathy among individuals with celiac disease. J Clin Gastroenterol. 2013;47:678-83.

17. Papista C, Lechner S, Ben Mkaddem S, LeStang MB, Abbad L, Bex-Coudrat J, et al. Gluten exacerbates IgA nephropathy in humanized mice through gliadin-CD89 interaction. Kidney Int. 2015;88:276-85.

18. Cheung CK, Barratt L. Gluten and IgA nephropathy: you are what you eat? Kidney Int. 2015;88:215-8.

19. Coppo R. The gut-kidney axis in IgA nephropathy: role of microbiota and diet on genetic predisposition. Pediatr Nephrol. 2018;33: 53-61.

20. Sevillano AM, Gutiérrez E, Yuste C, Cavero T, Mérida E, Rodríguez P, et al. Remission of hematuria improves renal survival in IgA nephropathy. J Am Soc Nephrol. 2017;28:3089-99.

21. Nicholls K, Walker RG, Dowling JP, Kincaid-Smith P. "Malignant" IgA nephropathy. Am J Kidney Dis. 1985;5:42-6.

22. Kincaid-Smith P, Nicholls K, Birchall I. Polymorphs infiltrate glomeruli in mesangial IgA glomerulonephritis. Kidney Int. 1989;36: 1108-11.

23. Rauen T, Eitner F, Fitzner C, Sommerer C, Zeier M, Otte B, et al. Intensive supportive care plus immunosuppression in IgA Nephropathy. N Engl J Med. 2015;373:2225-36.

24. Ieiri N, Hotta O, Sato T, Taguma Y. Significance of the duration of nephropathy for achieving clinical remission in patients with IgA nephropathy treated by tonsillectomy and steroid pulse therapy. Clin Exp Nephrol. 2012;16:122-9.

25. Vergano L, Loiacono E, Albera R, Coppo R, Camilla R, Peruzzi L, et al. Can tonsillectomy modify the innate and adaptive immunity pathways involved in IgA nephropathy? J Nephrol. 2015;28:51-8.

26. Bourges D, Wang CH, Chevaleyre C, Salmon H. T and IgA B lymphocytes of the pharyngeal and palatine tonsils: differential expression of adhesion molecules and chemokines. Scand J Immunol. 2004;60:338-50.

27. Horiguchi S. The discovery of the nasopharyngitis and its influence on general diseases. Acta Otolaryngol. 1975;29:1-120.

28. Hotta O, Tanaka A, Oda T. Chronic epipharyngitis: a missing background of IgA nephropathy. Autoimmun Rev. 2019;18(8):835-6. https://doi.org/10.1016/j.autrev.2019.06.002.

29. Hotta O, Tanaka A, Torigoe A, Imai K, Ieiri N. Involvement of chronic epipharyngitis in autoimmune (auto-inflammatory) syndrome induced by adjuvants (ASIA). Immunol Res. 2017;65:6671.

30. Takano K, Kojima T, Go M, Murata M, Ichimiya S, Himi T, et al. HLA-DR- and CD11c-positive dendritic cells penetrate beyond 
well-developed epithelial tight junctions in human nasal mucosa of allergic rhinitis. J Histochem Cytochem. 2005;3:611-9.

31. Fujimura $Y$. Evidence of $M$ cells as portals of entry for antigens in the nasopharyngeal lymphoid tissue of humans. Virchows Arch. 2000;36:560-6.

32. Boyaka PN, Wright PF, Marinaro M, Kiyono H, Johnson JE, Gonzales RA, et al. Human nasopharyngeal-associated lymphoreticular tissues. Functional analysis of subepithelial and intraepithelial $\mathrm{B}$ and $\mathrm{T}$ cells from adenoids and tonsils. Am $\mathrm{J}$ Pathol. 2000;57:2023-35.

33. Iwasaki A, Medzhitov R. Toll-like receptor control of the adaptive immune responses. Nat Immunol. 2004;5:987-95.

34. Akira S, Uematsu S, Takeuchi O. Pathogen recognition and innate immunity. Cell. 2006;124:783-801.

35. Gankovskaya LV, Bykova VP, Namasova-Baranova LS, Karaulov $\mathrm{AV}$, Rahmanova IV, Gankovskii VA, et al. Innate immunity gene expression by epithelial cells of upper respiratory tract in children with adenoid hypertrophy. Auris Nasus Larynx. 2018;45:753-9.

36. Suzuki H, Suzuki Y, Narita I, Aizawa M, Kihara M, Yamanaka T, et al. Toll-like receptor 9 affects severity of IgA nephropathy. J Am Soc Nephrol. 2008;19:2384-95.

37. Coppo R, Camilla R, Amore A, Peruzzi L, Daprà V, Loiacono E, et al. Toll-like receptor 4 expression is increased in circulating mononuclear cells of patients with immunoglobulin A nephropathy. Clin Exp Immunol. 2009;159:73-81.

38. Chang H, Yu DS, Liu XQ, Zhang QY, Cheng N, Zhang SQ, et al. Clinical significance of TLR3 and TLR4 in peripheral blood mononuclear cells from children with Henoch-Schönlein purpura nephritis. Exp Ther Med. 2014;7:1703-7.

39. Donadio ME, Loiacono E, Peruzzi L, Amore A, Camilla R, Chiale $\mathrm{F}$, et al. Toll-like receptors, immunoproteasome and regulatory $\mathrm{T}$ cells in children with Henoch-Schönlein purpura and primary IgA nephropathy. Pediatr Nephrol. 2014;29:1545-51.

40. Li W, Peng X, Liu Y, Liu H, Liu F, He L, et al. TLR9 and BAFF: their expression in patients with IgA nephropathy. Mol Med Rep. 2014;10:1469-74.

41. Saito A, Komatsuda A, Kaga H, Sato R, Togashi M, Okuyama S, et al. Different expression patterns of Toll-like receptor mRNAs in blood mononuclear cells of IgA nephropathy and IgA vasculitis with nephritis. Tohoku J Exp Med. 2016;240:199-208.

42. Imai T, Hieshima K, Haskell C, Baba M, Nagira M, Nishimura M, et al. Identification and molecular characterization of fractalkine receptor CX3CR1, which mediates both leukocyte migration and adhesion. Cell. 1997;91:521-30.

43. Jamieson WL, Shimizu S, D'Ambrosio JA, Meucci O, Fatatis A. CX3CR1 is expressed by prostate epithelial cells and androgens regulate the levels of CX3CL1/fractalkine in the bone marrow: potential role in prostate cancer bone tropism. Cancer Res. 2008;68:1715-22.

44. Garcia GE, Xia Y, Chen S, Wang Y, Ye RD, Harrison JK, et al. NFkappaB-dependent fractalkine induction in rat aortic endothelial cells stimulated by IL-1beta, TNF-alpha, and LPS. J Leukoc Biol. 2000;67:577-84.

45. Bjerkeli V, Damås JK, Fevang B, Holter JC, Aukrust P, Frøland SS. Increased expression of fractalkine (CX3CL1) and its receptor, CX3CR1, in Wegener's granulomatosis-possible role in vascular inflammation. Rheumatology. 2007;46:1422-7.

46. Cox SN, Sallustio F, Serino G, Loverre A, Pesce F, Gigante M, et al. Activated innate immunity and the involvement of CX3CR1 fractalkine in promoting hematuria in patients with IgA nephropathy. Kidney Int. 2012;82:548-60.

47. Iwatani H, Nagasawa Y, Yamamoto R, Iio K, Mizui M, Horii A, et al. CD16+CD56+ cells are a potential culprit for hematuria in IgA nephropathy. Clin Exp Nephrol. 2015;19:216-24.

48. Hotta O, Taguma Y, Yusa N, Ooyama M. Analysis of mononuclear cells in urine using flow cytometry in glomerular diseases. Kidney Int Suppl. 1994;47:S117-21.

49. Ouyang W, Kolls JK, Zheng Y. The biological functions of T helper 17 cell effector cytokines in inflammation. Immunity. 2008;28: 454-67.

50. Laan M, Cui ZH, Hoshino H, Lötvall J, Sjöstrand M, Gruenert DC, et al. Neutrophil recruitment by human IL-17 via C-X-C chemokine release in the airways. J Immunol. 1999;162:2347-52.

51. Peng MY, Wang ZH, Yao CY, Jiang LN, Jin QL, Wang J, et al. Interleukin 17-producing gamma delta $\mathrm{T}$ cells increased in patients with active pulmonary tuberculosis. Cell Mol Immunol. 2008;5: 203-8.

52. Takahashi N, Vanlaere I, de Rycke R, Cauwels A, Joosten LA, Lubberts E, et al. IL-17 produced by Paneth cells drives TNFinduced shock. J Exp Med. 2008;205:1755-61.

53. Iwakura $Y$, Ishigame H, Saijo S, Nakae S. Functional specialization of interleukin-17 family members. Immunity. 2011;34:149-62.

54. Dolff S, Wizke O, Wilde B. Th17 cells in renal inflammation and autoimmunity. Autoimmun Rev. 2019;18:129-36.

55. Yang S, Chen B, Shi J, Chen F, Zhang J, Sun Z. Analysis of regulatory $\mathrm{T}$ cell subsets in the peripheral blood of immunoglobulin $\mathrm{A}$ nephropathy (IgAN) patients. Genet Mol Res. 2015;14:14088-92.

56. Hidalgo A, Peired AJ, Wild M, Vestweber D, Frenette PS. Complete identification of E-selectin ligands on neutrophils reveals distinct functions of PSGL-1, ESL-1, and CD44. Immunity. 2007;26:477-89.

57. Gong Y, Zhang Y, Feng S, Liu X, Lü S, Long M. Dynamic contributions of $\mathrm{P}$ - and E-selectins to $\beta 2$-integrin-induced neutrophil transmigration. FASEB J. 2017;31:212-23.

58. Suzuki K, Hino M, Kutsuna H, Hato F, Sakamoto C, Takahashi T, et al. Selective activation of $\mathrm{p} 38$ mitogen-activated protein kinase cascade in human neutrophils stimulated by IL-1 $\beta$. J Immunol. 2001;167:5940-7.

Publisher's note Springer Nature remains neutral with regard to jurisdictional claims in published maps and institutional affiliations. 